\title{
Double Disaster: Mental Health of Survivors of Wildfires and Earthquake in a Part of Greece
}

\author{
Vicky Papanikolaou ${ }^{1}$, Dimitrios Adamis ${ }^{2,3}$, Robert C. Mellon ${ }^{4}$, \\ Gerasimos Prodromitis ${ }^{4}$, John Kyriopoulos ${ }^{1}$ \\ ${ }^{1}$ Department of Health Service Management, National School of Public Health, Athens, Greece; \\ ${ }^{2}$ Research and Academic Institute of Athens, Athens, Greece; \\ ${ }^{3}$ Institute of Psychiatry, Kings College, HSPR Department, London, UK; \\ ${ }^{4}$ Department of Psychology, Panteion University of Social and Political Sciences, Athens, Greece. \\ Email: bpapanikolaou@esdy.edu.gr, dimaadamis@yahoo.com, \{mellon,gprod\}@panteion.gr \\ Received December $16^{\text {th }}, 2010$; revised February $8^{\text {th }}, 2011$; accepted February $22^{\text {nd }}, 2011$
}

\begin{abstract}
This paper investigates stress related psychological morbidity in individuals who experienced two disasters 11 months apart (wildfire and earthquake) in a rural area of Greece. A sample of 150 participants has been assessed after the wildfires and after the earthquake using the Symptom Checklist 90-Revised. Survivors had elevated levels of psychopathology in all subscales of the SCL-90-R after the earthquake. Significant risk factors for further development of psychopathology were damages to property and complete loss of property from both disasters. Double disasters can cause considerable psychological symptoms in victims and there are reasons for policy makers to create services in order to help and improve the mental health of those affected but also to help them rebuild their property.
\end{abstract}

Keywords: Double Disaster, Greece, Psychopathology, Psychological Distress, Adults

\section{Introduction}

Natural disasters are frequent events in Greece. It is estimated that from 1980 to 2008, 61 natural disasters happened and the average number of people killed per year were 54 while the average number of affected people per year was 10,426 . Earthquakes and wildfires are among the most frequent natural disasters and they have also caused the most profound economic damages (EM-DAT, 2010).

In August of 2007 an intense and destructive wildfire broke out in the Peloponnesus peninsula in Greece. This was the worst of the century in Greece. The fires expanded rapidly and raged out of control for several days. Sixty to eighty people were reported killed and 5,392 people were affected from the disaster (EM-DAT, 2010). About 1,500 square kilometres of forests, olive trees, farmland, and villages were burned in these fires and the economic damages were estimated around 1,750,000 (X 1,000) US\$. A national disaster was declared and the areas affected by the fires were designated for further support.

A year later, in July 2008, a deadly earthquake hit the same area (Peloponnesus) with a moment magnitude of 6.5, according to the Athens Geodynamic Institute. The number of people killed varied in the reports from 2-6, the injured were more than 220 and at least 2,000 people were reported homeless. The number of affected people was estimated at around 3,708 (EM-DAT, 2010).

After the August wildfires it was perhaps the first time that the need for an effective public health planning for disasters was recognised, in order to deliver specific services and to provide sufficient resources for treating mental disorders, reducing symptoms, and preventing future problems to those affected by the disaster. In addition, it was recognised that it was necessary to estimate the impact of the natural disasters on the mental health of victims. Parts of this planning were also to carry out research and to evaluate the affected population mental health problems.

Although natural disasters differ widely, they usually have some common characteristics in terms of the risks of survivors' developing psychopathology and mental distress. Life threat, injury to oneself or family member, death of loved ones, and property loss were among the risk factors which have been indentified (Norris et al., 2002; Norris, Friedman, Watson, 2002). All of these factors exist typically in any natural disaster. The consequences of these disorders can be long lasting. In addition, a different kind of disaster may have a different impact on mental health (Norris, Friedman, Watson, 2002) and it has been suggested (Weiss, Saraceno, Saxena, \& van Ommeren, 2003) that it is important to distinguish continuing situations (e.g., ongoing war, ongoing drought) from acute ones, because chronic disasters result in simultaneous acute and ongoing disaster-related problems. However, the impact of double acute disasters in short time on the mental health of survivors is less studied.

Here, the present study investigates the psychological distress six months after the wildfires and one month after the earthquake in a selected community population subsample in the rural region of Peloponnesus, Greece.

In particular, the study aims to (a) assess the differences in the prevalence of psychopathology 6 months after the wildfires and one month after the earthquake, and (b) examine sociodemographic, and disaster related losses variables predictive of psychiatric caseness. 


\section{Method}

\section{Design of the Study}

The first phase of the study (6 months after the wildfires) was a cross sectional case control study. The two samples (cases and controls) were closely matched for gender, age, educational, marital and regional distributions. Participants were residents aged from 18 years to 65 years old who lived in the five prefectures designated by the Hellenic Republic Ministry of Interior to be disaster areas. The number of respondents surveyed in each prefecture was proportional to its adult population. The sample was composed of 409 residents of designated disaster areas and 391 residents of directly adjoining areas in which there was no fire damage in the immediate vicinity. For more details about the methods for this phase see (Mellon, Papanikolau, \& Prodromitis, 2009).

\section{Participants}

For the second phase of study which is examined here, the recruited population were a subsample $(n=150)$ of those affected from wildfires and who lived mainly in the affected from the earthquake area (see also Figure 1). They were reassessed in one month's time after the earthquake (five months after first assessment and 11 months after the wildfire disaster). The participants were residents aged from 18 years to 65 years old.

\section{Measurements}

1) Demographic characteristics (age, gender, educational background, marital status, occupation). All the demographic characteristics were self-reported. Age was categorised in five groups, education in three, marital status in four and occupation in three.
2) Symptom Checklist 90-Revised (SCL-90-R) (Derogatis \& Psychometric, 1992). A Greek validated version of SCL-90-R was used (Donias, Karastergiou, \& Manos, 1991). A sensitivity of 0.98 and a specificity of 0.74 in indicating active psychiatric patients of SCL-90-R were reported (Donias, Karastergiou, \& Manos, 1991). The SCL-90-R has 90 items, which measure the degree of distress experienced by the individual during the last 7 days, using a 5-point scale (0 to 4 ) that ranges from "not at all” to "extremely." The SCL-90R can be scored for nine symptom dimensions (Somatization, Obsessive-Compulsive, Interpesonal Sensitivity, Depression, Anxiety, Hostility, Phobic Anxiety, Paranoid, and Psychoticism). In addition to the nine scales, there are three global indices that are computed. The Global Severity Index (GSI), is the sum of all the nonzero responses, divided by 90, (if there are no missing responses) and reflects both the number of symptoms endorsed and the intensity of perceived distress. The Positive Symptom Total (PST) is defined as the number of symptoms to which the patient indicates a nonzero response. This is a measure of the number of symptoms endorsed. Thus, it can be interpreted as a measurement of symptoms span. The Positive Symptom Distress Index (PSDI) is calculated by dividing the sum of all item values by the PST; this is a measure of "intensity" corrected for the number of symptoms. The internal consistency reliability of SCL-90-R was found quite satisfactory ranging from a 0.77 for the dimension of Psychoticism to 0.90 for Depression. Similarly test retest reliability was found ranging from 0.78 for the dimension of Hostility to 0.90 for Phobic Anxiety. Regarding validity, the sensitivity of SCL-90-R to detect psychiatric cases was reported equal to 0.90 and specificity to 0.87 (Derogatis \& Psychometric, 1992).

3) Number and type of losses as a result of the fire or the earthquake including: a) damage to property (Yes vs. No), b)

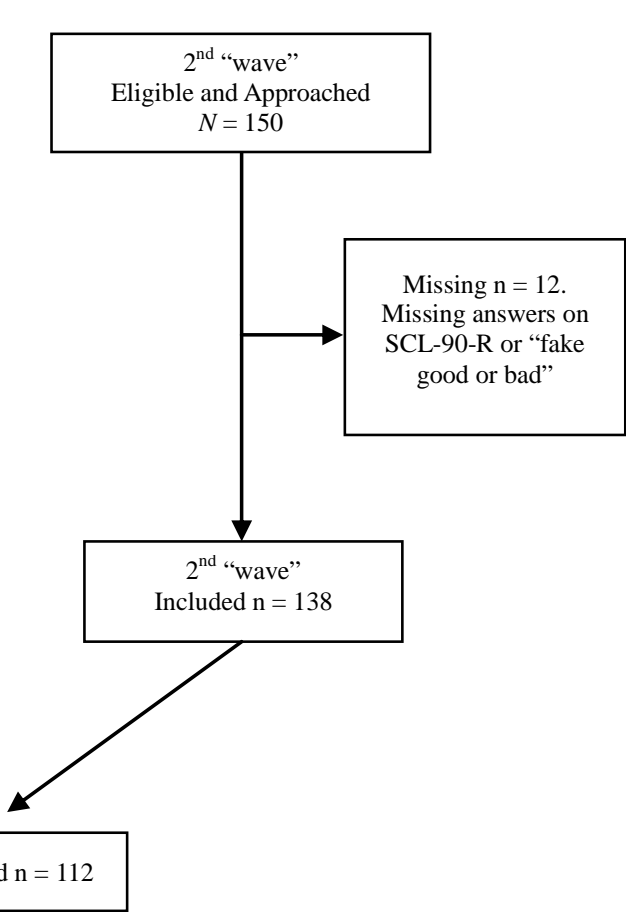

Figure 1.

Chart flow of participants. 
complete damage and loss of property (Yes vs. No), c) personal injury or injury of a close family member (Yes vs. No), and d) deaths of close family members (Yes vs. No). The responses to questions $\mathrm{a}$ and $\mathrm{b}$ were mutually exclusive. If more than one loss had happened all of them counted (number of losses). Also the types of losses were self-reported and the number of losses was calculated from the different types.

\section{Procedure}

Data were collected in face-to-face interviews. In the first wave of assessments interviewers asked if there was an adult in the random sampled household (at least 18 years of age) who would be willing to participate anonymously. In each household only one interview was conducted. In the second wave of assessments the same individual from the same household was asked again to participate in the survey.

\section{Ethics}

The study has been approved by the Ministry of Health and informed consent was obtained from each participant.

\section{Analysis}

The Q Local v 2.1.11, (NCS Pearson Inc, MN, USA), was used for the estimation of the standardized $\mathrm{T}$ scores from the raw data for the SCL-90-R scale. Data were analysed with PASW (SPSS) v18, using appropriate paired test statistics. For the non-normally distributed data, non-parametric tests were used. To estimate the effects of losses and individual characteristics on the caseness status, as it was recorded with the SCL-90-R scale, a multinomial logistic regression model was constructed.

\section{Results}

\section{Demographic Characteristics of the Sample}

A total number of 150 subjects took part in both "waves" of the survey, of whom 75 (50\%) were males. The demographic characteristics are presented in Table 1.

\section{Psychological Distress after the Wildfires and the Earthquake}

To investigate the differences of psychological symptoms as they were measured with the SCL-90-R scale between the two assessments (after wildfires and after the earthquake) a paired test was used. As the variables did not conform to a normal distribution, a non-parametric test was used (Wilcoxon Signed Ranks Test). Because of missing answers in SCL-90-R, or same answer in all 90 questions or fake "good or bad", the total number of participants analysed were $N=112$ (Figure 1). Table 2 shows some descriptive statistics $(N$, mean, $S D)$ of each variable and the statistical significance of the comparisons. As it can be seen from Table 2 all the participants had significantly increased psychological distress after the earthquake in all the measured symptoms and the three indices of SCL-90-R compared to the previous 5 months ago.

\section{Number and Type of Losses}

Table 3 shows the numbers and the percentages of the individuals who had each type of loss. The number of losses was estimated by adding each category of loss: the minimum is 0 and the maximum 3.

\section{Caseness}

A caseness, according to SCL-90-R, is when a respondent has a GSI score greater or equal to a T score of 63 or if any of two dimensions scores are greater than or equal to a $\mathrm{T}$ score of 63 . Thus, in the first wave of assessments $(n=112) 23$ cases were identified $(20.5 \%)$ while in the second $(n=138) 93$ cases (67.4\%). In the total analysed sample $(N=103) 23$ participants (22.3\%) were not cases in both assessments, 58 (56.3\%) were new cases, $15(14.6 \%)$ remained the same and 7 (6.8\%) have recovered. There was a significant increase of cases after the earthquake (McNemar Test, $x^{2}=38.462, d f: 1, p<.001$ ) compared to cases after the wildfires.

\section{Effects of Socio-Demographic Factors and Losses from the Disasters on the Caseness}

To further investigate the factors that significantly influence the caseness status (new cases, constantly cases, recovered cases, and never cases) a multinomial regression model was conducted. The caseness status (four levels) was the dependent variable and demographic characteristics (gender, age, education, occupation, and marital status), type of losses and the number of losses were the independent variables. Table 4 shows only the significant effects of the independent variables on the caseness status.

As it can be seen from Table 4 new cases were more likely to be those who had old and new damages to their property and those who have completely lost their property from both natural disasters compared to those who did not develop significant psychopathology (no cases in both assessments). However, they were less likely to have deaths of loved ones. In addition, those who were constantly cases in both waves of the survey were

Table 1.

Demographic characteristics of the sample.

\begin{tabular}{|c|c|c|c|}
\hline & & $\begin{array}{c}\text { Count } \\
\text { ( } \mathbf{N}=\mathbf{1 5 0})\end{array}$ & N\% \\
\hline \multirow{5}{*}{ Age group } & $18-25$ & 27 & 18.0 \\
\hline & $26-35$ & 31 & 20.7 \\
\hline & $36-45$ & 32 & 21.3 \\
\hline & $46-55$ & 32 & 21.3 \\
\hline & $56-65$ & 28 & 18.7 \\
\hline \multirow{3}{*}{ Education } & Primary school & 39 & 26.0 \\
\hline & Secondary school & 93 & 62.0 \\
\hline & College/university & 18 & 12.0 \\
\hline \multirow{4}{*}{ Marital status } & married & 103 & 68.7 \\
\hline & single & 41 & 27.3 \\
\hline & divorced & 1 & .7 \\
\hline & widowed & 5 & 3.3 \\
\hline \multirow{3}{*}{ Occupation } & professional occupation & 22 & 14.7 \\
\hline & sales and customer service occupation & 19 & 12.7 \\
\hline & elementary occupation & 109 & 72.7 \\
\hline
\end{tabular}


Table 2.

Comparison between the assessments.

\begin{tabular}{|c|c|c|c|c|c|}
\hline & $\mathrm{N}$ & Mean & Std. Deviation & $(1-2) \mathrm{Z}$ & Sig. (2-tailed) \\
\hline Somatisation 2 & 138 & 65.17 & 9.891 & \multirow{2}{*}{$-7.231^{\mathrm{a}}$} & \multirow{2}{*}{$p<.001$} \\
\hline Somatisation 1 & 112 & 50.62 & 11.296 & & \\
\hline Obsessive-compulsive (OC) 2 & 138 & 60.23 & 9.337 & \multirow{2}{*}{$-6.794^{\mathrm{a}}$} & \multirow{2}{*}{$p<.001$} \\
\hline Obsessive-compulsive (OC) 1 & 112 & 48.59 & 10.010 & & \\
\hline Interpersonal sensitivity (IS) 2 & 138 & 60.25 & 9.849 & \multirow{2}{*}{$-6.554^{\mathrm{a}}$} & \multirow{2}{*}{$p<.001$} \\
\hline Interpersonal sensitivity (IS) 1 & 112 & 49.21 & 8.680 & & \\
\hline Depression 2 & 138 & 63.06 & 9.099 & \multirow{2}{*}{$-6.750^{\mathrm{a}}$} & \multirow{2}{*}{$p<.001$} \\
\hline Depression 1 & 112 & 52.04 & 9.862 & & \\
\hline Anxiety 2 & 138 & 57.11 & 11.333 & \multirow{2}{*}{$-5.935^{\mathrm{a}}$} & \multirow{2}{*}{$p<.001$} \\
\hline Anxiety 1 & 112 & 47.55 & 10.558 & & \\
\hline Hostility 2 & 138 & 55.51 & 10.005 & \multirow{2}{*}{$-4.587^{\mathrm{a}}$} & \multirow{2}{*}{$p<.001$} \\
\hline Hostility 1 & 112 & 49.33 & 9.666 & & \\
\hline Phobic anxiety 2 & 138 & 58.90 & 10.295 & \multirow{2}{*}{$-5.171^{\mathrm{a}}$} & \multirow{2}{*}{$p<.001$} \\
\hline Phobic anxiety 1 & 112 & 51.86 & 7.933 & & \\
\hline Paranoid 2 & 138 & 62.22 & 10.792 & \multirow{2}{*}{$-6.269^{\mathrm{a}}$} & \multirow{2}{*}{$p<.001$} \\
\hline Paranoid 1 & 112 & 51.46 & 10.459 & & \\
\hline Psychotism 2 & 138 & 56.30 & 10.786 & \multirow{2}{*}{$-5.743^{\mathrm{a}}$} & \multirow{2}{*}{$p<.001$} \\
\hline Psychotism 1 & 112 & 47.47 & 7.428 & & \\
\hline GSI 2 & 138 & 63.09 & 9.226 & \multirow{2}{*}{$-7.454^{\mathrm{a}}$} & \multirow{2}{*}{$p<.001$} \\
\hline GSI 1 & 112 & 48.95 & 11.053 & & \\
\hline PSDI 2 & 138 & 58.72 & 7.137 & \multirow{2}{*}{$-6.377^{\mathrm{a}}$} & \multirow{2}{*}{$p<.001$} \\
\hline PSDI 1 & 112 & 50.53 & 9.634 & & \\
\hline PST 2 & 138 & 61.91 & 8.995 & \multirow{2}{*}{$-7.098^{\mathrm{a}}$} & \multirow{2}{*}{$p<.001$} \\
\hline PST 1 & 112 & 48.59 & 11.464 & & \\
\hline
\end{tabular}

a. Based on positive ranks.

Table 3.

Number and type of losses in the two waves of assessments.

\begin{tabular}{lccc}
\hline & & $\begin{array}{c}\text { First wave n } \\
\text { (\%) }\end{array}$ & $\begin{array}{c}\text { Second wave n } \\
\text { (\%) }\end{array}$ \\
\cline { 2 - 4 } damages to property & No & $58(38.7)$ & $30(20)$ \\
& Yes & $92(61.3)$ & $120(80)$ \\
complete loss of property & No & $117(78)$ & $125(83.3)$ \\
& Yes & $33(22)$ & $25(16.7)$ \\
injuries of individual or & No & $144(96)$ & $141(94)$ \\
close members of the family & Yes & $6(4)$ & $9(6)$ \\
deaths of close members & No & $141(94)$ & $138(92)$ \\
& Yes & $9(6)$ & $12(8)$ \\
the number of losses & 0 & $21(14)$ & $8(5.3)$ \\
& 1 & $118(78.7)$ & $120(80)$ \\
& 2 & $11(7.3)$ & $20(13.3)$ \\
& 3 & - & $2(1.3)$ \\
\hline
\end{tabular}

more likely to be males (borderline significance) and those who had completely lost their property in both disasters.

\section{Discussion}

The results show that the one disaster after another increases the psychopathology of the survivors. Only few victims had recovered (in terms of psychopathology) from the first disaster during the five months time and none of the examined factors contributed significantly to their recovery. Previous research in survivors of disasters has showed that the psychological distress and psychopathology after disasters are long lasting (Norris et al., 2002; Norris, Friedman, Watson, 2002; Weiss et al. 2003). Those who were constantly cases during the five months' time were more likely to be males and to have completely lost their property by the two disasters. It seems that during the time between the disasters, they had tried to rebuild their property but the new disaster destroyed everything again. This perhaps explains why the male gender was a risk factor. Culturally in Greece and especially in rural areas males are 
Table 4.

Parameter Estimates (only significant results) from multinomial analysis.

\begin{tabular}{|c|c|c|c|c|c|c|}
\hline & Caseness $^{\mathrm{a}}$ & B & Std. Error & Wald & df & Sig. \\
\hline & Intercept & 17.963 & 2.803 & 41.070 & 1 & $* *$ \\
\hline & Not at all damages & -0.829 & 1.955 & 0.180 & 1 & NS \\
\hline & New damages & -0.284 & 0.787 & 0.131 & 1 & NS \\
\hline & Old damages & -3.332 & 1.489 & 5.009 & 1 & $*$ \\
\hline & Old and new damages & $0^{\mathrm{b}}$ & . & . & 0 & \\
\hline & Complete loss of property (no) & -20.122 & 1.971 & 104.224 & 1 & $* *$ \\
\hline & Complete loss of property (New) & -16.836 & 2.230 & 57.025 & 1 & $* *$ \\
\hline & Complete loss of property (Old) & -18.919 & 1.811 & 109.176 & 1 & $* *$ \\
\hline & Complete loss of property (old and new) & $0^{\mathrm{b}}$ & . & . & 0 & \\
\hline & Deaths (no) & 2.806 & 1.218 & 5.308 & 1 &.$*$ \\
\hline & Deaths (New) & 0.268 & 1.583 & 0.029 & 1 & NS \\
\hline & Deaths (Old) & $0^{\mathrm{b}}$ & . & . & 0 & \\
\hline $\begin{array}{l}\text { Old caseness } \\
(\text { recovered } n=7 \text { ) }\end{array}$ & No significant effects of examined variables & & & & & \\
\hline & Intercept & 19.764 & 2.759 & 51.315 & 1 & $* *$ \\
\hline & Male & 1.789 & 0.911 & 3.858 & 1 & $*$ \\
\hline old and new & Female & $0^{\mathrm{b}}$ & . & . & 0 & . \\
\hline$($ constantly caseness $=15)$ & Complete loss of property (no) & -20.101 & 1.217 & 272.957 & 1 & $* *$ \\
\hline & Complete loss of property (New) & -18.357 & 1.692 & 117.674 & 1 & $* *$ \\
\hline & Complete loss of property (old and new) & $0^{\mathrm{b}}$ & . & . & 0 & \\
\hline
\end{tabular}

a. The reference category is: no caseness in both assessments; $\mathrm{b}$. This parameter is set to zero because it is redundant; Statistical significant $p<.05$ marked ${ }^{*}, p<.001$ marked $* *$, NS $=$ no significance

responsible for the building and the maintenance of property thus conceivably they are under more stress. Although the female gender has been identified in literature as a risk factor to develop psychopathology after disasters (Norris et al., 2002) not all the studies agree with it (e.g. Den Ouden, 2007) while others reported that females are more likely to develop depression or phobia (Heir \& Weisaeth, 2008; Hussain, Weisaeth \& Heir, 2010). In addition, when we analysed the data separately, ignoring the first wave of assessments we did not find any significant effect of gender on the caseness (analysis was not reported in the results). Similarly, analysis of the total sample of the wildfires victims (first wave of assessments), gender was found not to influence the caseness but females were more likely to develop somatisation symptoms (Unpublished data). However, a previous study after a series of disasters (storm, tornado, floods, exposure to dioxin) in St. Louis area (USA) in 1982 (Solomon, Smith, Robins, \& Fischbach, 1987) reported that males and females differ in how they display negative effects of disaster exposure. Males showed increased symptoms of alcohol abuse and depression as a result of either personal, or both personal and indirect, exposure to disaster, while the psychopathology of females was not affected by the personal exposure to disaster. Thus males are more prone to develop symptomatology in directed exposure to disaster compared to females (Solomon, Smith, Robins, \& Fischbach, 1987).

Furthermore, those who became new cases in terms of psychopathology after the earthquake were those who had property losses in both disasters. It seems that the new losses had an additive effect on the development of psychopathology. Although material losses seem to be a risk factor for caseness, it is surprising that injuries to oneself or to a family member had not any effect. In addition, deaths of loved ones seem to be a protective factor for psychological caseness. However, it is important to note here that the number of deaths was small, so the power to detect true differences is low. Also, the official number of deaths reported for the second disaster (earthquake) was two, and those two (if not more) have accounted for twelve (affected) survivors. This could happen as the disaster area was rural and the family ties are perhaps tighter. On the contrary, the number of injured was high but injuries did not have any effect on psychopathology. However, similar findings have been reported by others (Heir \& Weisaeth, 2008; Clayer, Bookless-Pratz, \& Harris, 1985). In fact, Heir and Weisaeth (Heir \& Weisaeth, 2008) pointed out that having a near relative or close friend injured could be a protective factor because of distraction, and because a caretaking role for a close relative may increase resilience and self efficacy.

This study also has limitations. First of all, the number of participants in the second wave of assessments and inevitably the comparison with the first wave of assessments is relatively small. Because, as we discussed above, the number of deaths was small, maybe the effect of deaths on psychological distress is wrongly estimated. Since the number of participants was fixed from the first wave of assessments and given that the study was purely observational and pragmatic we could not increase the number of participants at the second wave of as- 
sessments. Similarly, we have found some risk factors from variables which we have measured and maybe other unobserved factors have also influenced the psychopathology in both disasters. A second more important limitation of this study is that the sample may be biased. In the second wave of assessments the sample was not random as in the first. Simply, we followed-up those who participated in the first part of the study and we have included those who lived in the most affected from the earthquake area (prefecture of Ilia). Thus, it is very likely that we have compared a less affected from wildfires population with the most affected from the earthquake and thus the differences in psychopathology perhaps were more pronounced. In addition, the time of assessments after the disaster was unequal. Our data can only be interpreted in one way; that is, a disaster after another increases psychological distress. On the other hand, despite these limitations this study is maybe the first which examined the impact of two "acute" natural disasters on the mental health of victims.

Thus, it seems from the above that two natural disasters in relatively short time increase the psychological distress of the affected population. Risk factors for further development of psychopathology are damages to property and complete loss of property. It can also be concluded that it takes time for the psychological distress to cease after a disaster.

These findings have implications for policy makers, disaster response agencies, and communities affected by disaster. If the losses are risk factors for producing psychological distress then efforts to protect positions or to replace them to some degree may reduce distress and thus reduce the impact of disaster on a community.

Our findings are similar with general disaster literature despite cultural differences. Loss of property and income together with life threat were significantly related to distress in previous studies e.g. (Gibbs, 1989; O’Neill et al., 1999; Freedy et al., 1994; Smith, \& Freedy, 2000).

Thus there are reasons for policy makers not only to create services in order to help and improve the mental health of those affected but also to support victims in restoring their properties.

\section{Acknowledgements}

The study has been funded by the Ministry of Health \& Social Solidarity within the framework of Health Disaster Management in cooperation with World Association for Disaster Emergency Medicine.

\section{References}

Clayer, J. R., Bookless-Pratz, C., \& Harris, R. L. (1985). Some health consequences of a natural disaster. Medical Journal of Australia, 143, 182-184.

Den Ouden, D. J., Van Der Velden, P. G., Grievink, L., Morren, M.,
Dirkzwager, A. J. E., \& Yzermans, C. J. (2007). Use of mental health services among disaster survivors: Predisposing factors. BMC Public Health, 7, 173. doi:10.1186/1471-2458-7-173

Derogatis, L. R. \& Psychometric, R. C. (1992). SCL-90-R: Administration, scoring \& procedures manual-II, for the revised version and other instruments of the psychopathology rating scale series. Clinical Psychometric Research, Towson.

Donias, S., Karastergiou, A., \& Manos, N. (1991). Standardization of the symptom checklist 90 rating scale in a Greek population. Psychiatriki, 2, 42-48.

EM-DAT. (2008). The OFDA/CRED International Disaster Database PreventionWeb, Louvain Centre for Research on the Epidemiology of Disasters, Ecole de Santé Publique, Université Catholique de Louvain.

http://www.preventionweb.net/english/countries/statistics/index.php? cid=68.” Retrieved 15/9/2010..

Freedy, J. R., Saladin, M. E., Kilpatrick, D. G., Resnick, H. S., \& Saunders, B. E. (1994) Understanding acute psychological distress following natural disaster. Journal of Trauma Stress, 7, 257-273. doi:10.1002/jts.2490070207

Gibbs, M. S. (1989). Factors in the victim that mediate between disaster and psychopathology: A review. Journal of Traumatic Stress, 2, 489514. doi:10.1002/jts.2490020411

Heir, T. \& Weisaeth, L. (2008). Acute disaster exposure and mental health complaints of Norwegian tsunami survivors six months post disaster. Psychiatry, 71, 266-276. doi:10.1521/psyc.2008.71.3.266

Hussain, A., Weisaeth, L., \& Heir, T. (2010, In Press) Psychiatric disorders and functional impairment among disaster victims after exposure to a natural disaster: A population based study. Journal of Affective Disorders.

Mellon, R. C., Papanikolau, V., \& Prodromitis, G. (2009). Locus of control and psychopathology in relation to levels of trauma and loss: Self-reports of Peloponnesian wildfire survivors. Journal of Trauma Stress, 22, 189-196. doi:10.1002/jts.20411

Norris, F. H., Friedman, M. J., Watson, P. J., Byrne, C. M., Diaz, E., \& Kaniasty, K. (2002). 60,000 disaster victims speak: Part I. An empirical review of the empirical literature, 1981-2001. Psychiatry, 65, 207-239. doi:10.1521/psyc.65.3.207.20173

Norris, F. H., Friedman, M. J., \& Watson, P. J. (2002). 60,000 disaster victims speak: Part II. Summary and implications of the disaster mental health research. Psychiatry, 65, 240-260. doi:10.1521/psyc.65.3.240.20169

O'Neill, H. K., Evans, B. A., Bussman, M. D., \& Strandberg, D. K. (1999). Psychological distress during the Red River flood: Predictive utility of the Conservation of Resources model. Applied Behavioral Science Review, 7, 159-169. doi:10.1016/S1068-8595(00)80016-1

Smith, B. W. and Freedy, J. R. (2000) Psychosocial resource loss as a mediator of the effects of flood exposure on psychological distress and physical symptoms. Journal of Trauma Stress, 13, 349. doi:10.1023/A:1007745920466

Solomon, S., Smith, E. M., Robins, L., \& Fischbach, R. L. (1987) Social involvement as a mediator of disaster-induced stress. Journal of Applied Social Psychology, 17, 1092-1112. doi:10.1111/j.1559-1816.1987.tb02349.x

Weiss, M. G., Saraceno, B., Saxena, S., \& van Ommeren, M. (2003). Mental health in the aftermath of disasters: Consensus and controversy. Journal of Nervous and Mental Disease, 191, 611-615. doi:10.1097/01.nmd.0000087188.96516.a3 